\title{
Karbon / Azot Oranının Organik Toprakların Bazı Özellikleri Üzerine Etkisi
}

\author{
Rawaz Khasro QADER Hüseyin Dikici* Ömer Faruk DEMiR \\ Kahramanmaraș Sütçü İmam Üniversitesi, Toprak Bilimi ve Bitki Besleme Bölümü, Kahramanmaraș
}

*Sorumlu yazar e-posta (Corresponding author e-mail): hdikici@ksu.edu.tr

DOI: 10.21657/topraksu.338308

Öz

Bu çalıșma C/N oranının Kahramanmaraș İli, Sağlık Ovası organik topraklarının bazı toprak özellikleri üzerine olan etkisini belirlemek amacıyla yürütülmüștür. Bu amaç için alandan 50 adet toprak örneği alınmıș, analizleri yapılımıș, daha sonra veri seti hesaplanan C/N oranlarına göre üç farklı gruba ayrılmıștır. Grup 1 en düșük C/N oranlarına sahip iken grup 3 en yüksek C/N oranlarını içermiștir. Analizi yapılan toprak özelliklerinden pH, elektriksel iletkenlik, katyon değișim kapasitesi, kireç içeriği, organik madde, toplam azot, organik karbon ve bitkice alınabilir P, Mg, Na, Cu, Zn ve Mn konsantrasyonları üzerine C/N oranlarının etkisi istatistiksel olarak önemli bulunurken, bitkiye yarayıșlı Ca ve K bu değișimlerden etkilenmemiștir. C/N oranı grup 1'den grup 3'e doğru arttıkça, organik madde, organik karbon, pH, KDK, MVR ve CDFA yöntemleriyle hümik asit değerleri de artıș göstermiștir. Bu sonuçlar C/N oranlarının organik topraklarda toprak kalitesinin bir göstergesi olarak kullanılabileceğini göstermektedir.

Anahtar Kelimeler: C/N oranı, humik asit, organik toprak, toprak degradasyonu

\section{Effect of Carbon to Nitrogen Ratio on Some Properties of Organic Soils}

\begin{abstract}
This study was performed to determine the effect $\mathrm{C} / \mathrm{N}$ ratio on some properties of organic soils in Sağlık Plain, Kahramanmaraș. To achieve this objective, 50 soil samples were collected from the area and analyzed for some soil attributes, and data set were divided into three almost equally numbered groups based on the calculated C/N ratio values. The group 1 had the lowest $\mathrm{C} / \mathrm{N}$ ratios, and the group 3 had the highest among the three. The measured soil attributes such as $\mathrm{pH}$, electrical conductivity, cation exchange capacity, lime content, organic matter, total nitrogen, organic carbon, and extractable $\mathrm{P}, \mathrm{Mg}, \mathrm{Na}, \mathrm{Cu}, \mathrm{Zn}$, and $\mathrm{Mn}$ were significantly affected by $\mathrm{C} / \mathrm{N}$ ratios except for plant available Ca and $\mathrm{K}$. As $\mathrm{C} / \mathrm{N}$ ratio increased from group 1 to 3 , soil organic matter, organic $\mathrm{C}$, soil $\mathrm{pH}$, CEC, humic acid contents by MVR and CDFA methods also increased significantly. The results showed that $\mathrm{C} / \mathrm{N}$ ratio can be used as an indicator of soil quality in organic soils.
\end{abstract}

Key Words: C/N ratio, humic acids, organic soil, soil degradation

\section{Giriș}

Toprak organik karbonu ve azotu, sürdürülebilir toprak kalitesi, bitkisel üretim ve çevresel etkilerden açısından oldukça önemli bir role sahiptir (Bauer ve Black, 1994; Doran ve Parkin, 1994). Organik materyalin C/N oranı mikroorganizmalar tarafından açığa çıkarılan $\mathrm{CO}_{2}$ gazına oranla ne kadar azotun mineralize olacağını gösterir. Topraklarda C/N oranı 8 ile 17 arasında değișkenlik gösterir (Alistair, 1979) ve bu oran toprak kalitesi için oldukça önemli bir indekstir (Zhang vd., 2011). $\mathrm{Bu}$ oran ayrıca $\mathrm{pH}$, besin maddesi birikimini ve toprakta hümik madde içeriğini de etkilemektedir (Yano vd., 2000). Berg ve McClaugherty (2003) humus tabakaların kalınlığı ile C/N oranı arasında pozitif bir ilișki olduğunu bildirmiștir. 
Toprak ișleme organik maddenin parçalanmasına yol açar, ișlenen topraklarda C/N oranının daha dar olduğu bildirilmisțir (Seeber ve Seeber, 2005). Orman topraklarının tarım topraklarına göre daha yüksek C/N oranına sahip olduğu da rapor edilmiștir (John vd., 2005; Puget ve Lal, 2005).

Hümik maddeler doğal olarak olușan, biyogenetik ve heterojen yapıda, siyahtan sarıya değișen renkleriyle kolaylıkla tanımlanabilen, yüksek moleküler ağırlığa sahip ve parçalanmaya karșı dayanıklı materyallerdir (Sparks, 2003). Hümik maddeler fulvik asit, hümik asit ve hümin olarak sınıflandırılırlar. Fulvik asitler, hümik asitlere göre daha yüksek C/N oranına sahiptir (Anderson ve Hepburn, 1986). Hümik olmayan organik materyaller mikroorganizmalarca kolaylıkla parçalanır ve toprakta daha kısa süre kalırlar (Schnitzer ve Kahn, 1972; Sparks, 2003).

Sulak alanlarda önemli düzeylerde organik karbon bulunmaktadır ve peat materyallerinde organik maddenin \%60-85'i hümik maddelerdir (Garnier-Sillam vd., 1999). Organik topraklar drene edildiğinde, temel fonksiyonları olan su ve karbon rezervleri olma görevleri yerine birer sera gazı kaynağı haline gelirler (Okruszko, 1993).

Karbon ve azot arasındaki oran humifikasyon ișleminin bir indeksi olarak değerlendirilebilir (Brady, 1990; Miller ve Gardiner, 1998). Bu oran ayrıca organik topraklarda degradasyonun bir ölçüsü olarak da kullanılabilir. Bu orandaki azalmalar degradasyonun artmasının bir göstergesi olabilir. Bu çalıșmanın amacı drene edildiği 1950'li yıllardan bu yana önemli değișimlere uğrayan Sağıı Ovası organik topraklarının C/N oranlarının diğer toprak özellikleri üzerine etkisini araștırmaktır.

\section{MATERYAL VE YÖNTEM}

Bu çalıșmada araștırma materyali olarak Kahramanmaraș İli, Sağlık Ovası organik toprakları kullanılmıștır. Bölgeden yanmamıș organik topraklardan ve birbirine komșu yaklașık 4 tarladan, $0-30 \mathrm{~cm}$ derinlikten 50 adet toprak örneği alınmıștır. Çalıșma alanı ile ilgili detaylı bilgiler Dikici ve Yılmaz (2006) tarafından verilmektedir. Kurutulan toprak örnekleri öğütülüp polietilen torbalara konulmuștur. Böylece analize hazır hale getirilmiștir. Toprak örneklerinde EC tayini YSI 32 marka elektriksel iletkenlik aleti ile saturasyon çamurunda (Rhoades, 1996), $\mathrm{pH}$ tayini yine saturasyon camurunda WTW-Inolab marka pH metre ile (Thomas, 1996) ve organik madde modifiye edilmiș Walkley-Black yöntemine (Nelson ve Sommers, 1996) göre belirlenmistir. Toplam kireç Gülçur (1974), toprakların katyon değișim kapasitesi ise sodyum asetat kullanılarak belirlenmiștir (Chapman, 1965). Toprak ve bitki örneklerinde toplam N Kjeldahl yöntemine göre belirlenmiștir (Bremner, 1996). Bitkiye yarayıșlı Ca, $M g$ ve $\mathrm{K}$ ve ekstrakte edilebilir $\mathrm{Na} 1 \mathrm{~N}$ amonyum asetat $\left(\mathrm{NH}_{4} \mathrm{OAC}, \mathrm{pH}=7\right)$ yöntemiyle (Helmke ve Sparks, 1996) ve Atomik Absorbsiyon Spektrofotometresi (Perkin Elmer, 3110 ) aletinde belirlenmiștir. Bitkiye yarayıșlı fosfor 0,5 M $\mathrm{NaHCO}_{3}$ yöntemiyle (KuO, 1996) Optima SP-3000 spektrofotometresinde, ekstrakte edilebilir Zn, Cu ve $\mathrm{Mn}$ ise DTPA yöntemiyle Perkin Elmer 3110 AAS ile belirlenmiștir (Lindsay ve Norvell, 1978).

Toprak örneklerinde hümik asit tayini Türk Standartları Enstitüsü (Anonim, 2003), Mesa Verda Resources (MVR) (Reid, 1999) ve Kaliforniya Gıda ve Tarım Departmanı (CDFA) (Page, 1982) yöntemlerine göre tayin edilmiștir.

Çalıșma sonunda tüm istatistiksel analizler SPSS programı kullanılarak yapılmıștır. Farklı C/N grupları varyans analizi ve Duncan çoklu karșılaștırma testi ile karșılaștırılmıștır. Buna göre uygulamalar arasındaki farklar, p değeri 0,05'ten küçükse $(p<0,05)$ önemli olarak kabul edilmiștir.

\section{BULGULAR VE TARTISMA}

Organik topraklarda yapılan bazı fiziksel ve kimyasal analizlerin sonuçları çizelge l'de verilmiștir. Toprakların $\mathrm{pH}$ değerleri 6,80 ile 7,53 arasında değișmiș, ortalama değer 7,22 olarak bulunmuștur. Organik topraklar için ana materyale bağlı olarak benzer, daha düșük ve daha yüksek $\mathrm{pH}$ değerleri rapor edilmiștir (Bascomb, 1964; Ponnamperuma, 1972; Collins vd., 1997; Bridgham ve Richardson, 1993). Saturasyon çamurunda ölçülen ve 1,78 ile 3,70 dS $\mathrm{m}^{-1}$ arasında değișen elektriksel iletkenlik değerleri bu topraklarda tuzluluk probleminin bir göstergesidir. Toprakların katyon değișim kapasitesi 35,20 ve 90,10 $\mathrm{cmol}_{\mathrm{c}} \mathrm{kg}^{-1}$ arasında değișmiș ve ortalama değer ise $68,37 \mathrm{cmol}_{\mathrm{c}} \mathrm{kg}^{-1}$ olarak bulunmuștur (Çizelge 1). Toprakların kireç içerikleri ise \% 4,82'nin altında bulunmuștur.

Organik topraklarda organik karbon değerleri $\% 12,50$ ile \%30,60, organik madde içerikleri ise 
\% 21,50 ile \% 52,70 arasında bulunmuștur (Çizelge 1). Toprakların ortalama organik karbon ve organik madde değerleri sırasıyla \%22,81 ve \%39,82 olarak hesaplanmıștır. Leeper ve Uren (1993) yaptıkları çalıșmada peat toprakları için organik madde içeriklerini \% 27-33 olarak bildirmișlerdir. Toplam azot \%1,39-2,55, C/N oranları ise 8,99-13,20 aralıklarında bulunmuștur. Organik topraklara ait \% 0,5 ile \% 2,6 arasında değișen toplam azot değerleri diğer araștırmacılar tarafından da rapor edilmiștir (Kaila, 1958; Scheffer, 1976).

Toprakların hümik asit içerikleri üç farklı yöntem (TSE, MVR ve CDFA) ile Ölçülmüș ve değerler TSE yöntemi için \%6,00-15,20, MVR yöntemi için \% 1,67-5,23 ve CDFA yöntemi için \%2,58-30,57 aralığında bulunmuștur. Türk Standartları Enstitüsü metodu yaș yakma yöntemi ile hem hümik hem de fulvik asitleri ekstrakte etmektedir (Anonim, 2003). Bulgular Bozkurt (2005)'in peat toprakları için bildirdiğine benzer (\%5-15) fakat Çelik (2003) tarafından bildirilen değerlere (\% 15-30) göre daha düșüktür. Mesa Verda Resources (MVR) yöntemi kalorimetrik olarak sadece hümik asitleri ölçtüğü için diğer iki yönteme göre daha düșük değerler ortaya koymuștur.

Organik topraklarda analizi yapılan bitkiye yarayıșlı makro- ve mikro-elementlerin analiz sonuçları Çizelge 2'de verilmiștir. Genel olarak toprakların bitkiye yarayıșlı Ca ve Mg içeriklerinin oldukça yüksek, bitkiye yarayıșlı P ve K içeriklerinin ise düșük olduğu bulunmuștur. Bitkiye yarayıșlı $\mathrm{Cu}, \mathrm{Zn}$ ve Mn içerikleri mineral topraklar için yeterli kategoride yer alsa da organik topraklar için bu değerler düșüktür.

Karbon/azot oranının toprak özellikleri üzerine olan etkisini araștırmak için veri seti hesap edilen C/N oranına göre küçükten büyüğe sıralanıp ve bu sıralamaya göre üç gruba ayrılmıștır. Sıralama ile Grup 1 en düșük ve Grup 3 ise en yüksek C/N oranına sahip örnekleri kapsamıștır (Çizelge 3).

Çizelge 1. Ölçülen bazı kimyasal ve fiziksel toprak parametrelerine ait özet istatistikler

Table 1. Summary statistics of the some properties of organic soils

\begin{tabular}{lccc}
\hline & Minimum & Maksimum & Ortalama \\
\hline $\mathrm{pH}$ & 6,80 & 7,53 & 7,22 \\
$\mathrm{EC}\left(\mathrm{dS} \mathrm{m}{ }^{-1}\right)$ & 1,78 & 3,70 & 3,19 \\
$\mathrm{KDK}\left(\mathrm{cmolc} \mathrm{kg}^{-1}\right)$ & 35,20 & 90,10 & 68,37 \\
Kirec $(\%)$ & 2,10 & 4,80 & 3,77 \\
$\mathrm{OM}(\%)$ & 21,50 & 52,70 & 39,32 \\
$\mathrm{OC}(\%)$ & 12,50 & 30,60 & 22,81 \\
$\mathrm{~N}(\%)$ & 1,39 & 2,55 & 2,05 \\
$\mathrm{C} / \mathrm{N}$ & 8,99 & 13,20 & 11,00 \\
$\mathrm{H} . \mathrm{A}(\mathrm{TSE}, \%)$ & 6,00 & 15,20 & 10,30 \\
H.A (MVR, \%) & 1.67 & 5.23 & 3,33 \\
H.A (CDFA, \%) & 2,58 & 30,57 & 16,56 \\
\hline
\end{tabular}

Çizelge 2. Ölçülen bitkice alınabilir makro ve mikro elementlere ait özet istatistikler

Table 2. Summary statistics of plant available macro and micro-nutrients in organic soils

\begin{tabular}{lccc}
\hline & Minimum & Maksimum & Ortalama \\
\hline $\mathrm{P}\left(\mathrm{mg} \mathrm{kg}^{-1}\right)$ & 6,01 & 11,27 & 8,41 \\
$\mathrm{Ca}\left(\mathrm{mg} \mathrm{kg}^{-1}\right)$ & 6634,87 & 10904,50 & 8941,64 \\
$\mathrm{Mg}\left(\mathrm{mg} \mathrm{kg}^{-1}\right)$ & 2994,80 & 5426,08 & 4183,30 \\
$\mathrm{~K}\left(\mathrm{mg} \mathrm{kg}^{-1}\right)$ & 32,27 & 120,88 & 63,96 \\
$\mathrm{Na}\left(\mathrm{mg} \mathrm{kg}^{-1}\right)$ & 36,30 & 60,09 & 47,43 \\
$\mathrm{Cu}\left(\mathrm{mg} \mathrm{kg}^{-1}\right)$ & 0,42 & 1,27 & 0,91 \\
$\mathrm{Mn}\left(\mathrm{mg} \mathrm{kg}^{-1}\right)$ & 2,88 & 11,48 & 7,61 \\
Zn $\left(\mathrm{mg} \mathrm{kg}^{-1}\right)$ & 1,58 & 3,38 & 2,54 \\
\hline
\end{tabular}


Çizelge 3. Toprak örnekleri için olușturulan C/N gurupları

Table 3. Soil groups based on C/N ratios

\begin{tabular}{lc}
\hline C/N Gurupları & C/N Aralıkları \\
\hline Gurup 1 & $8,99-10,29$ \\
Gurup 2 & $10,30-11,70$ \\
Gurup 3 & $11,71-13,20$ \\
\hline
\end{tabular}

Çizelge 4. C/N oranına göre toprak özelliklerinin istatistiksel karșılaștırılması

Table 4. Statistical comparisons of some soil properties among the different $\mathrm{C} / \mathrm{N}$ groups

\begin{tabular}{|c|c|c|c|c|c|c|c|c|c|c|}
\hline $\begin{array}{l}\text { C/N } \\
\text { Gurupları }\end{array}$ & $\%$ O.M & $\% O C$ & $\% N$ & $\mathrm{pH}$ & $\mathrm{ECdS} \mathrm{m}^{-1}$ & $\begin{array}{c}\mathrm{KDK} \\
\mathrm{cmol}_{c} \mathrm{~kg}^{-1}\end{array}$ & $\%$ Kirec & $\begin{array}{c}\% H . A \\
\text { TSE }\end{array}$ & $\begin{array}{c}\% \mathrm{H} . \mathrm{A} \\
\text { MVR }\end{array}$ & $\begin{array}{l}\% \text { H.A } \\
\text { CDFA }\end{array}$ \\
\hline 1 & $31,02 \mathrm{c}$ & $18,00 \mathrm{c}$ & $1,85 b$ & $7,01 \mathrm{C}$ & $2,93 \mathrm{~b}$ & $59,15 c$ & $3,43 b$ & $8,70 b$ & $2,27 c$ & $9,76 c$ \\
\hline 2 & $38,79 b$ & $22,49 b$ & $2,05 b$ & $7,22 \mathrm{~b}$ & & $69,03 \mathrm{~b}$ & & $10,02 b$ & $3,07 b$ & $15,38 b$ \\
\hline 3 & $48,72 a$ & $28,26 a$ & $2,28 \mathrm{a}$ & $7,43 a$ & $3,47 a$ & $77,46 a$ & $4,32 \mathrm{a}$ & $12,28 \mathrm{a}$ & $4,75 a$ & $25,05 a$ \\
\hline
\end{tabular}

Çizelge 5. C/N oranına göre toprak özelliklerinin istatistiksel karșılaștırılması

Table 5. Statistical comparisons of some soil properties among the different C/N groups

\begin{tabular}{lcccccccc}
\hline C/N & $\begin{array}{c}\mathrm{P} \\
\text { Gurupları }\end{array}$ & $\begin{array}{c}\mathrm{Mg} \\
\mathrm{mg} \mathrm{kg}^{-1}\end{array}$ & $\begin{array}{c}\mathrm{Ca} \\
\mathrm{mg} \mathrm{kg} \mathrm{kg}^{-1}\end{array}$ & $\begin{array}{c}\mathrm{K} \\
\mathrm{mg} \mathrm{kg}^{-1}\end{array}$ & $\begin{array}{c}\mathrm{Na} \\
\mathrm{mg} \mathrm{kg}^{-1}\end{array}$ & $\begin{array}{c}\mathrm{Mn} \\
\mathrm{mg} \mathrm{kg}^{-1}\end{array}$ & $\begin{array}{c}\mathrm{Zn} \\
\mathrm{mg} \mathrm{kg}^{-1}\end{array}$ & $\begin{array}{c}\mathrm{Cu} \\
\mathrm{mg} \mathrm{kg}^{-1}\end{array}$ \\
\hline 1 & $7,79 \mathrm{~b}$ & $4006,05 \mathrm{~b}$ & 8708,78 & 57,14 & $45,52 \mathrm{~b}$ & $6,43 \mathrm{~b}$ & $2,21 \mathrm{~b}$ & $0,83 \mathrm{~b}$ \\
2 & $8,08 \mathrm{~b}$ & $4065,07 \mathrm{~b}$ & 8710,25 & 63,97 & $46,13 \mathrm{~b}$ & $7,45 \mathrm{~b}$ & $2,60 \mathrm{a}$ & $0,91 \mathrm{ab}$ \\
3 & $9,44 \mathrm{a}$ & $4497,25 \mathrm{a}$ & 9434,90 & 71,20 & $50,85 \mathrm{a}$ & 9,04a & $2,84 \mathrm{a}$ & $1,00 \mathrm{a}$ \\
\hline
\end{tabular}

Karbon/azot oranı arttıkça toprak organik maddesi, organik karbon, $\mathrm{pH}, \mathrm{KDK}, \mathrm{MVR}$ ve CDFA yöntemi ile hümik asit içerikleri de artıș gösterdi. Organik azot, elektriksel iletkenlik, kireç içeriği ve TSE yöntemi ile hümik asit içeriği ise C/N oranının en yüksek olduğu gurupta diğer iki gruptan istatistiksel olarak daha yüksek bulundu (Çizelge 4). Bu çalıșmadaki bulgulara benzer șekilde, Leeper ve Uren (1993) C/N oranındaki artıș ile toprakların $\mathrm{pH}$ ve KDK'Iarının arttığını rapor etmiștir.

Bitkice alınabilir makro ve mikro besin elementlerinin $\mathrm{C} / \mathrm{N}$ oranı ile değișimi incelendiğinde, $\mathrm{P}, \mathrm{Mg}$, Na ve $\mathrm{Mn}$ yarayıșılıı̆ının en yüksek C/N oranı grubunda (Grup 3) artıș gösterdiği, gruplar arasında bitkiye yarayıșlı Ca ve $\mathrm{K}$ açısından istatistiksel bir fark olmadığı bulunmuștur (Çizelge 5). Bitkice alınabilir Mn açısında Grup 1 istatistiksel olarak Gruplar 2 ve 3'ten daha düșük olarak bulundu. Bitkiye yarayıșlı Cu ise en yüksek C/N oranına sahip grupta, Grup l'e göre daha yüksek olarak ölçüldü.

Bu çalıșma ile $\mathrm{C} / \mathrm{N}$ oranı ile ölçülen diğer toprak özellikleri arasında önemli ilșkiler bulunmuștur, bu bulgular C/N oranlarının organik topraklarda toprak kalitesinin bir göstergesi olarak kullanılabileceğini göstermektedir.

\section{SONUÇLAR}

Sağlık ovası organik toprakları 1950'li yılların sonlarında drene edilmiș ve zamanla alan tarıma açılmıștır. Alandaki organik topraklar gerek oksidasyonunun artması gerek ise çıkan yangınlarla önemli değișimlere uğramıșlardır. Geride kalan organik toprakların korunması için çalıșmalar yapılmaktadır. Bu çalıșma ile C/N oranı ile ölçülen toprak özellikleri arasında önemli ilșkiler bulunmuștur, bu bulgular C/N oranlarının organik topraklarda toprak kalitesinin bir göstergesi olarak kullanılabileceğini göstermektedir. Karbon/azot oranındaki azalmalar topraklarda degradasyonun bir ölçüsü olarak değerlendirilmiștir. Sağlık ovası organik topraklarının tarım alanı olarak kullanılmasının topraklarda degradasyonu arttıracağı ve așırı kullanılacak azotlu gübrelerin de süreci hızlandırabileceği düșünülmektedir.

\section{Teșekkür}

Bu çalıșma Kahramanmaraș Sütçü İmam Üniversitesi Bilimsel Araștırma Projeleri Bașkanlığı tarafindan desteklenmiștir (2014/2-40YLS).

\section{KAYNAKLAR}

Alistair F (1979). Pitty Geography and soil properties, Taylor and Francis. 
Anderson H, Hepburn A (1986). Variation of humic substances within peat profile. In: Peat and water (Ed. C. H. Fuchsman), N.Y.: Academic Press, 177-194.

Anonim (2003). Türk Standardı TS 5869 ISO 5073. Kahverengi kömürler ve linyitlerde humik asitlerin tayini.

Bascomb C L (1964). Rapid method for the determination of cation exchange capacity of calcareous and non-calcareous soils. J. Sci. Food Agric. 15:821-823.

Bauer A, Black $A L$ (1994). Quantification of the effect of soil organic matter content on soil productivity. Soil Sci. Soc. Am. J. 58, 185-193.

Berg B, McClaugherty C (2003). Plant litter: decomposition, humus formation, carbon sequestration. SpringerVerlag, Berlin-Heidelberg, Germany. 286 pp.

Bozkurt M (2005). Ayrıșma Dereceleri Farklı Peatlerin Humik Asit Kapsamlarının İi Ayrı Yöntemle Karșılaștııılması. A.Ü.Fen Bilimleri Enstitüsü. Yayınlanmamıș Yüksek Lisans Tezi.

Brady N C (1990). The Nature and Properties of Soils. Tenth edition. Macmillan Publ. Co., New York, NY.

Bremner J M (1996). Nitrogen Total. in D.L. Sparks (Eds) Methods of Soil Analysis, Part 3, Chemical Methods, SSSA Book Series Number 5, SSSA., Madison,WI, P:1085-112.

Bridgham S D, Richardson C J (1993). Hydrology and nutrient gradients in North Carolina peatlands. Wetlands 13:207-218.

Chapman H D (1965). Cation-exchange capacity. In: C.A. Black (ed.). Methods of soil analysis - Chemical and microbiological properties. Agronomy 9:891-901.

Collins D W, Maydew E L, Weiss I S (1997). Changes in the value-relevance of earnings and book values over the past forty years. Journal of Accounting and Economics, 24(1), 39.

Çelik C (2003). Tabiat ananın gizemli hediyesi; humik maddeler (II), Hasad Dergisi, Yıl: 19, Sayl: 217.

Dikici H, Yllmaz C H (2006). Peat Fire Effects on Some Properties of an Artificially Drained Peatland. J. Environ. Qual., 35(3):866-870.

Doran JW, Parkin T B (1994). Defining and assessing soil quality. Doran, J.W., et al., (Eds.), Defining Soil Quality for a Sustainable Environment. Special Publication No. 35. Soil Science Society of America, Madison, WI, pp. 3-21.

Garnier-Sillam E, Hariyento S, Bourezgui Y (1 999). Humic substances in peats. Analysis, 27(5), 405-408.

Gülçur F (1974). Topragın Fiziksel ve Kimyasal Analiz Metodları, İstanbul Üniversitesi Orman Fakültesi Yayınları, İ. Ü. Yayın No: 1970, O. F. Yayın No: 201, Kutulmuș Matbaası, İstanbul.

Helmke PA, Sparks D L (1996). Lithium, Sodium, Potassium, Rubidium, and Calcium, in Sparks, D.L., (Eds). Methods of Soil Analysis, Part 3, Chemical Methods, SSSA Book Series Number 5, SSSA., Madison,WI, P:551-574.

John B, Yamashita T, Ludwig B, Flessa H (2005). Storage of organic carbon in aggregate and density fractions of soils under different types of land use. Geoderma. 128:63-79.

Kaila A (1958). Effect of superphosphate on the mobilization of nitrogen in a peat soil. J. Sci. Agric. Soc.
Finland, 30:114-124

Kuo S (1996). Phosphorus. (Methods of Soil Analysis: Chemical Methods. Part 3. Madison, WI., USA: Ed. Sparks, D.L.) 869-921.

Leeper GW, Uren N C (1993). Soil science, an introduction (5th edn ed.). Melbourne: Melbourne University Press. ISBN $0-522-84464-2$.

Lindsay, W.L., ve Norvell, W.A., (1978). Development of a DTPA Micronutrient Soil Test for Zinc, Iron, Manganese, and Copper. SSSA. Journal, 42:421-428.

Miller R W, Gardiner D T (1998). Soils in Our Environment. Eight edition. Prentice Hall, Upper Saddle River, NJ.

Nelson D W, Sommers L E (1996). Total Carbon, Organic Carbon, and Organic Matter. in D.L. Sparks (Eds) Methods of Soil Analysis, Part 3, Chemical Methods, SSSA Book Series Number 5, SSSA., Madison,WI, P: 961 1011. Odin, S., Huminsauren. Th. Steinkopff, Dresden und Leipzig, 1922, 199 pp.

Okruszko H (1993). Transformation of fen-peat soils under the impact of draining. Zeszyty Problemowe Postepow Nauk Rolniczych, 406:3-73.

Page A L (1 982). Methods of Soil Analysis Part 2, American Society of Agronomy, Inc., Madison, Wisconsin.

Ponnamperuma F N (1972). The chemistry of submerged soils. Adv. Agron. 24:29-96.

Puget P, Lal R (2005). Soil organic carbon and nitrogen in a Mollisol in central Ohio as affected by tillage and land use. Soil and Tillage Research. 80: 211-213.

Reid B (1999). University of New Mexico, Owner of Mesa Verde Resources.

Rhoades J D (1996). Salinity: Electrical conductivity and total dissolved gasses. p. 417-437. In D.L. Sparks (ed.) Methods of soil analysis. Part 3. SSSA Book Ser. 5. SSSA, Madison, WI.

Scheffer B (1976). Nitrogen transformations in fen soils (in German). Landwirtschaftliche Forschung, 33:20-28, J.D. SauerlInder's Verlag, Frankfurt-am-Main, Germany.

Schnitzer M, Khan S U (1972). Humic Substances in the Environment. Marcel Dekker, Inc., New York, NY.

Seeber J, Seeber G U H (2005). Effects of landuse changes on humus forms on alpine pastureland (Central Alps, Tyrol). Geoderma. 124:215-222.

Sparks D L (2003). Environmental Soil Chemistry 2nd Ed., Academic Press, Amsterdam, The Netherlands.

Thomas G W (1996). Soil pH and Acidity. (Methods of Soil Analysis: Chemical Methods. Part 3. Madison, WI., USA: Ed. Sparks, D.L.) 475-491.

Yano Y, McDowell W H, Aber J D (2000). Biodegra-dable dissolved organic carbon in forest soil solution and effects of chronic nitrogen deposition. Soil Biology and Biochemistry $32,1743-1751$

Zhang C H, Wang Z M, Ju W M, Ren C Y (201 1). “Spatial and Temporal Variability of Soil C/N Ratio in Songnen Plain Maize Belt," Environmental Science, Vol. 32, No. 5, pp. 1407-1414. 